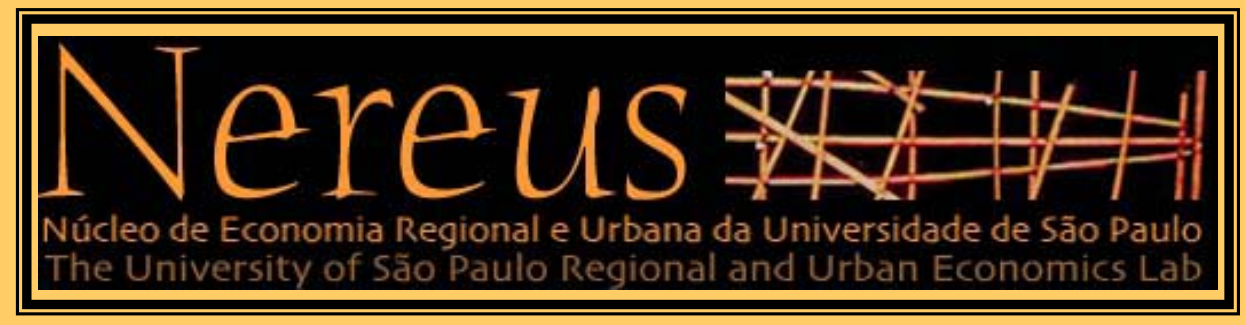

\title{
INVESTMENT DECISIONS IN TROUBLED TIMES: A BAYESIAN APPROACH APPLIED TO BRAZILIAN FIRMS
}

Aquiles Elie Guimarães Kalatzis

Carlos R. Azzoni

Jorge Alberto Achcar

TD Nereus 07-2005

São Paulo 2005 


\title{
Investment decisions in troubled times: a Bayesian approach applied to Brazilian firms
}

\author{
Aquiles Elie Guimarães Kalatzis ${ }^{*}$ \\ Carlos Roberto Azzoni** \\ Jorge Alberto Achcar ${ }^{* * *}$
}

\begin{abstract}
This study analyses the investment decision of 497 Brazilian firms during a period of unstable macroeconomic conditions. The role of financial constraints is considered in a Bayesian econometric model. We use panel data, with firm-specific information for different years. We estimate three different models, and the results indicate the presence of financial restrictions, especially for capital-intensive firms. The recursive predictive density criterion indicates that the most preferred model is the one in which firm-specific effects are correlated with cash flow. Financial restrictions are more important for capital-intensive firms, probably due to their lower profitability indexes, higher fixed costs and higher degree of property diversification.
\end{abstract}

Key Words: Investment Decisions, Financial Restrictions, Panel Data, Capital Intensity.

JEL Classification: G300; G310; G320

\section{1 - Introduction}

Investment is a key macroeconomic variable in any economic growth study. Disentangling the factors behind investment decisions is thus a very important topic, especially for less developed countries. The theory indicates that the development of financial markets and instruments result in a reduction in transaction and information costs, influencing saving rates and investment decisions. Many authors have dealt with the relationship between

\footnotetext{
* Department of Production Engineering, University of São Paulo School of Enginneering, Brazil ${ }^{* *}$ Department of Economics University of São Paulo, Brazil.

*** Department of Statistics, Federal University of São Carlos, São Paulo, Brazil.
} 
financial development and growth, such as King and Levine (1993), Levine (1997), Stiglitz (1990), Hafer and Jansen (1991), Rajan and Zingales (1998), Levine, Loayaza and Beck (2000). In Brazil, investment decisions were analyzed usually in relation to macroeconomic policy, given the important role of the state in the economy. This was the case until the mid80s, when the private sector increased its role in financing investment. In the 90s, limitations faced by firms and high interest rates were serious obstacles. The Brazilian economy became more open to foreign trade and investments, and the volatility caused by balance of payments shocks was transferred to the internal economy, mainly through exchange rate fluctuations and high interest rates, thus aggravating credit restrictions.

The banking sector was opened to foreign companies and capital market regulations were slowly improved, but these modifications have not substantially changed the pattern of private investments financing in Brazil. Basically, the Brazilian financial system is not equipped to provide long term financing to companies, except for the state-owned development banks, which have a small market share. Total credit supply amonts to $27 \%$ of GDP, and bonds issued by firms are less than 3\% of GDP. Pinheiro and Cabral (1998) have indicated that this limited supply is due to high real interest rates, high banking spread, noncompliance, and inefficiecy of the judicial system. The stock market is still limited to a small number of firms and is highly sensitive to speculative moves of large scale dealers. Moreira and Puga (2001) have shown that internally generated resources are the main source of financing for Brazilian firms, what imposes a restriction on investment and to economic growth at the national level. Thus, Brazilian firms finance their investments basicaly with internal resources.

The objective of this study is to identify the principal determinants of investment of a sample of Brazilian companies. We use data in panel form, considering the non-observed heterogeneous behavior of firms through a specific component for each firm. A time component is introduced to consider the non-observable time effects which affect all firms. In order to correct for heteroskedasticity, firms were grouped by capital intensity. We estimate three Bayesian econometric models. The greater flexibility of the Bayesian approach permits the introduction of an interaction variable combining time and firm-specific effects, and the introduction of a firm-specific effect correlated with the cash flow variable. The consideration of the degree of capital intensity of firms, the introduction of an interaction variable and the analysis of firm-specific effects correlated with the independent variable represent novel contributions to the discussion on the presence of liquidity restrictions on Brazilian firms. 


\section{2 - Investment Decisions by the Firm}

Over the last few years, the main discussions on investment decisions refer to the effects of financial restrictions on investment. A firm is considered to be financially restricted if the cost or availability of external financing prevents it from realizing new projects that it would have selected if internal financing had been available (Kaplan and Zingales, 1995). For Bond and Reenen (2002), a firm is financial restricted if an unexpected increase in the availability of internal funds causes an increase in investment spending, not related to potential future profitability. The widespread recognition that these restrictions play an important role arises from results obtained in various empirical studies. The fundamental question relates to the form of classifying companies, in such a way that effects arising from financial restrictions may be checked and adequately isolated. Fazzari, Hubbard and Petersen (1988) grouped the companies by the dividend payout ratio to shareholders, finding that sensitivity to cash flow was greater for companies classified as low dividend payers. The authors inferred the existence of a monotonically increasing relationship between sensitivity of investment to cash flow and the degree of credit restriction.

Kaplan and Zingales (1997), there is no strong theoretical reason for the sensitivity of cash flow to investment to be a monotonic function either of internal funds available to companies or of problems regarding the degree of information asymmetry. The authors used the same database as Fazzari et al. (1988), demonstrating that the relationship between investment sensitivity and cash flow could be of another nature, rather than proof of liquidity problems. They reexamined the same sample of 49 companies grouped by the low degree of dividend distribution, subsequently arranging these into five categories, according to their respective operating performance. The authors found that $85 \%$ of these firms could not be considered as financially restricted, since they had scope for increasing their investments by using credit lines or cash reserves. They also concluded that firms with lower restrictions showed greater sensitivity of investment to cash flow than firms classified as more restricted. Hoshi, Kashyap and Scharfstein (1991) grouped Japanese firms by the closeness of their banking relations, finding that firms with closer banking ties were subject to lower restrictions on their cash flow. The study by Blundell et al. (1992) of investment by British firms confirmed that cash flow was positive and significant. Bond and Meghir (1994) carried out an empirical investigation of 626 British companies, finding that failure to check for any type of financing regime can lead to excessive sensitivity to internal funds. Hsiao and 
Tahmiscioglu (1997) grouped 561 U.S. companies by degree of capital intensity, and concluded that a disregard for differences in the individual behavior of firms, with equal parameters for all of these, led to serious underestimation of the coefficients of the variables.

Such studies and several others have shown that the form of classification of companies is fundamental in indicating the presence of financial restrictions. Firms considered in this study were classified by degree of capital intensity, unlike the majority of other studies carried out for the Brazilian economy. We assume that internal funds are not perfect substitutes to external funds, and that firms are subject to liquidity constraints on their investment decisions. We use a version of the Accelerator model initially proposed by Jorgenson (1963), incorporating the concept of capital cost to describe the behavioral dynamic of investment with regard to growth in a firm's output ${ }^{1}$.

The model used in this study, as synthesized in Equation 1 below, is a version of the Accelerator model, in which we attempt to explain investment behavior with regard to variations in firm's output.

$$
\left(\frac{I}{K}\right)_{j t}=\alpha+\beta_{1}\left(\frac{I}{K}\right)_{j t-1}+\beta_{2}\left(\frac{I}{K}\right)_{j t-1}^{2}+\beta_{3}\left(\frac{C F}{K}\right)_{j t-1}+\beta_{4}\left(\frac{S}{K}\right)_{j t-1}+\beta_{5}\left(\frac{D}{K}\right)_{j t-1}+\varepsilon_{j t}
$$

where $I_{k j t}$ is the firm's investment, defined as $K_{t}-K_{t-1} ; t$ is the year, ranging from 1 to $T ; j$ is the firm, ranging from 1 to $N$; $K_{j t}$ is the capital stock (fixed assets); $C F_{j t}$ is cash flow; $S_{j t}$ is sales; $D_{j t}$ is the total financing of the company and $\varepsilon_{j t}$ is the error term.

Since all variables are divided by capital stock, investment is measured as a rate, and the other variables are represented as ratios to capital stock. The choice of variables was made considering the extensive existing literature on investment theory. These studies assume the existence of a known investment function, in which the heterogeneity of firms may be considered by including a specific effect for each firm. The cash flow variable captures the effect of possible liquidity restrictions on investment behavior, although it may also represent potential for future profitability. The introduction of corporate debt derives from the idea of the tax benefits of debt, as well as the notion that higher leverage may increase firm value. As mentioned above, some authors have maintained that the degree of leverage is positively correlated with improvements in operating efficiency. The use of lagged

\footnotetext{
${ }^{1}$ This model assumes that investment behavior is a function of the total sales of a company, but does not consider the firm's growth expectations. For further details, see Abel and Blanchard (1986).
} 
values of the dependent variable together with lagged values of the predictors seeks to consider the dynamic aspect of investment behavior, as well as to avoid autocorrelation ${ }^{2}$. The quadratic variable was introduced due to indications of non-linear behavior of residuals, as will be observed in the exploratory analysis of the data, as well as to reflect a quadratic form of cost adjustment.

\section{3 - Data}

We use a sample of 497 private firms, with yearly information for the period 1986-97. During this period, Brazil underwent significant transformations, including an international moratorium in 1987 and six economic stabilization plans. The database was provided by the Instituto Brasileiro de Economia [Brazilian Institute of Economics] of the Getúlio Vargas Foundation (IBRE/FGV) and was collected by Gazeta Mercantil and Diário Oficial.

Figure 1 compares the evolution of investment by the companies included in the sample to the evolution of aggregate domestic investment, gross fixed capital formation. We may note major oscillations in private sector investment, with a larger number of periods of decline prevailing, most notably in the years 1990 and $1994^{3}$. In 1990, the Brazilian economy contracted by $5.05 \%$ of GDP, seriously affecting private investment, due to a recessionary economic policy. In 1994, the implementation of another economic stabilization plan, which included restrictive credit measures and increases in interest rates, had a negative impact on investment. It can be observed that a similar behavior of the two variables was also observed for most of the period under analysis, with the exception of 1991-92 and 1993-94. An interesting aspect indicated by Figure 2 is the occurrence of negative investment rates in 1990 and 1994, wich was more intense for the companies in the sample than for the economy as a whole. It is to be expected that corporate investment will be more vulnerable to periods of recession than aggregate investment, which includes other items less affected by the business cycle, such as public investment, investment in agriculture, construction, housing, etc. In

\footnotetext{
${ }^{2}$ Despite persistent criticism that the parameters may be biased due to the problem of endogeneity, Monte Carlo studies carried out by Hsiao, Pesaran and Tahmiscioglu (1997) with a dynamic panel for different Bayesian methods, found that the hierarchical Bayesian estimator performed well even over a short time period. On the simulation carried out by several models the authors had used a time period betwen 5 and 20, and the best perfomance is of bayesian hierarchical model even for a $T=5$, inferior than used in this work. To more details see Hsiao, Pesaran and Tahmiscioglu (1997).

${ }^{3}$ A simple regression of investment on time was estimated, confirming a significant declining trend over the period.
} 
years close to the implementation of economic stabilization plans, the variations in the sample are particularly notable.

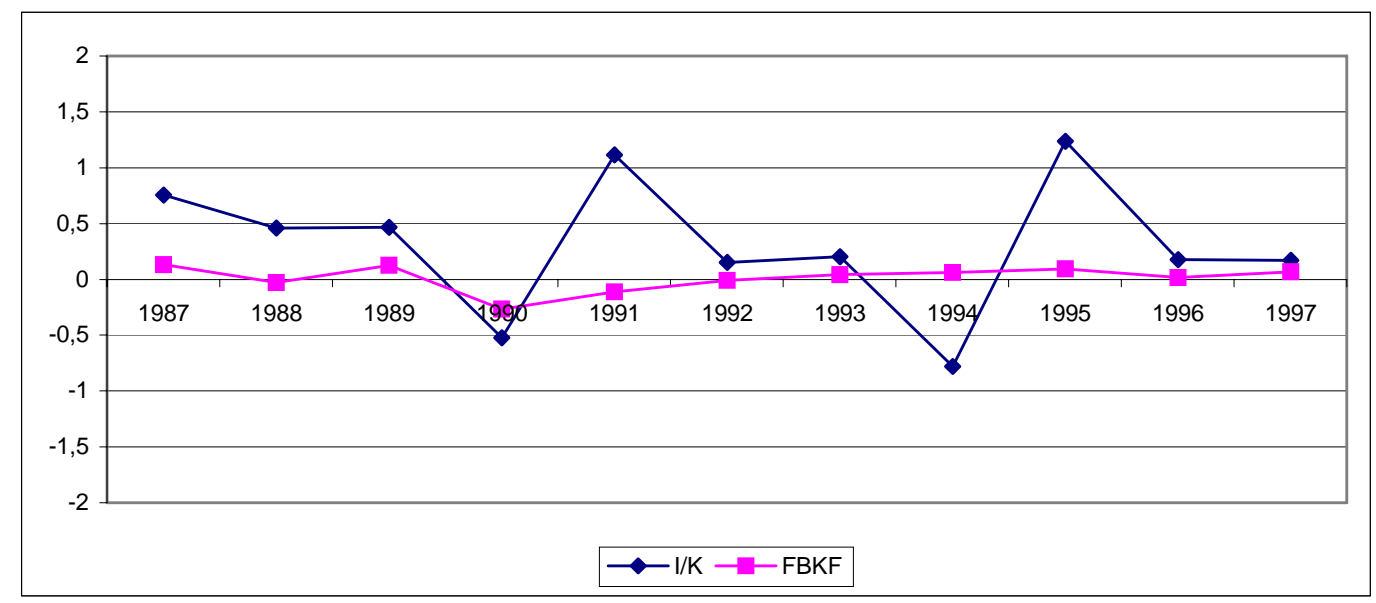

Figure 1-Aggregate investment (Gross Fixed Capital Formation) and investment by firms analyzed $(\mathrm{I} / \mathrm{K})$.

Source: FBKF - Conjuntura Econômica, (FGV), May 2003.

In order to reduce hererogeneity, firms were classified according to capital intensity, defined by the ratio of capital stock to sales plus changes in inventories of finished goods, $\frac{K}{S+\Delta E}$, following Jorgenson (1968). The choice of the cut-off point between high and low capital intensity considered the same criterion adopted by Hsiao and Tahmiscioglu (1997). Figure 2 shows the dispersion of the liquidity variable against the degree of capital intensity. From a visual inspection of the graph, we adopted a cut-off point of 0.15 . We ran a standard regression of the investment rate on the explanatory variables, and applied the test presented by Chow (1960), rejecting the null hypothesis that the coefficients are the same for the two samples. 


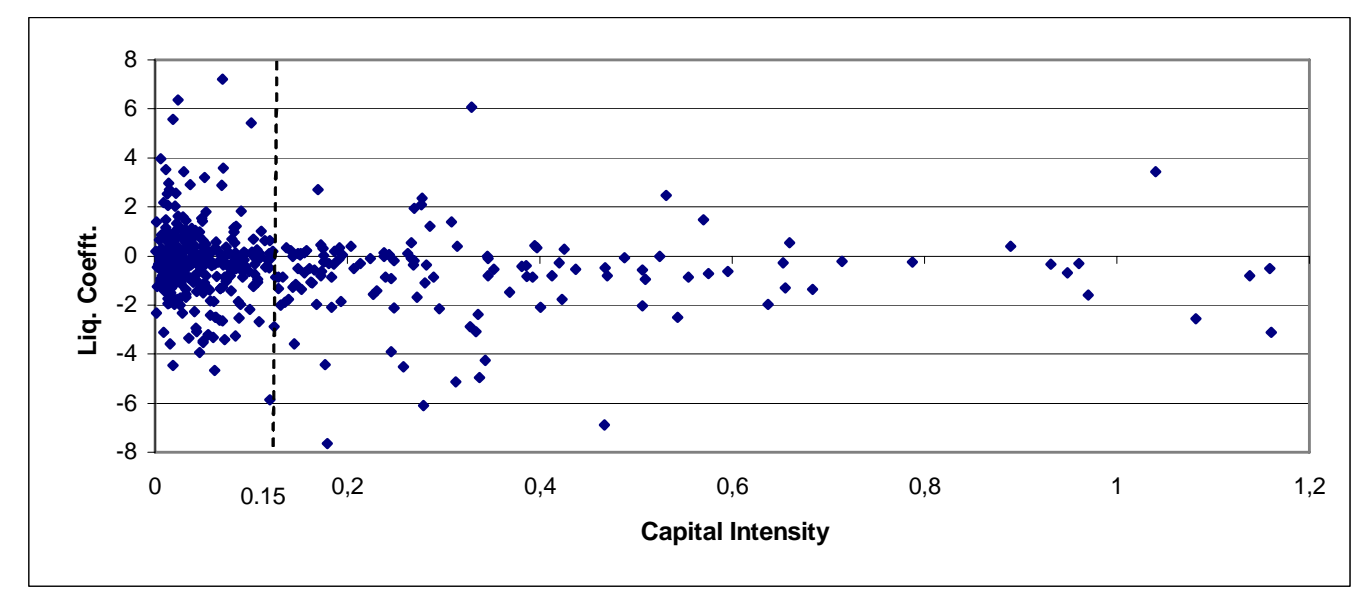

Figure 2 - Liquidity coefficients and capital intensity.

The classification of firms by degree of capital intensity plays an important role in the results obtained in this study. We believe that this classification offers a better way of controlling and separating the effects of financial restrictions from other factors ${ }^{4}$. Among the firms analyzed in this study, the rate of investment is more strongly correlated with capital intensity than with size, principally when we compare large firms with capital intensive ones. While the index of correlation between investment rate and capital intensity is 0.0406 , the correlation between firm size and investment rate is 0.0268 , indicating that the requirement for a marginal increase in capital depends more on the degree of capital intensity than on firm size $^{5}$. On the other hand, an analysis of investment decisions that only considers size may present a certain ambiguity, since it mixes maturities and sectors with distinct characteristics.

Table 1 shows the classification of the firms on the sample according to size and capital intensity. As can be noted, firms classified as highly capital intensive are always large, but the contrary does not hold, since many large companies are not capital intensive. In a simple regression exercise, as these large firms are introduced into the sample, the values of the liquidity and financing coefficients fall. These results suggest that capital intensity is more important than size for differentiating the importance of investment for firms. Schiantarelli and Devereux (1990) present an analysis of investment behavior by size, maturity and sector,

\footnotetext{
4 "The threat of obsolescence and the attractiveness of new and better machines make the capitalists with expensive machinery more accumulation-minded than entrepreneurs with relatively little capital input. [...]. The emphasis on reinvestment can, therefore, yield an argument for investment in more capital-intensive industries than would be indicated by a pure market calculation (p. 470).” Hirschman and Sirkin (1958)

${ }^{5}$ The estimation of a regression between the investment rate and the variables of size and capital intensity corroborated the greater importance of the latter in explaining the variability of the investment rate.
} 
showing that the cash flow effect tends to be larger for young firms and firms in growing sectors. While it is reasonable to consider most young firms as small firms, the same does not hold for firms in growing sectors. On the other hand, the results show that cash flow plays a more important role for large firms. This indicates the existence of a certain common and ambiguous influence when firms are merely classified by size ${ }^{6}$.

Table 1 - Distribution of Firms by Capital Intensity and Size.

\begin{tabular}{ccccc}
\multicolumn{5}{c}{ Size } \\
Capital Intensity & & Small & Large & Total \\
& Low & 1,146 & 2,586 & 3,732 \\
& High & --- & 1,238 & 1,238 \\
& Total & 1,146 & 3,824 & 4,970 \\
\hline
\end{tabular}

Table 2 presents the mean values for the principal variables for each group. Cash flow, sales, net income and working capital (all as ratios to capital stock) show higher values for low-intensity firms less. The higher mean value of sales for firms with lower capital intensity may represent a greater need to maintain a reserve of liquid assets in order to mitigate periods of high revenue volatility. These numbers are similar to those found in the study by Scherer (1980), in which firms with a higher degree of capital intensity showed a lower ratio of cash flow to capital stock. The higher fixed cost of more capital intensive companies would cause the majority of economic performance indicators to register higher values for low capital intensity firms. In the case of the former kind of firm, low values for cash flow, net income and change in net working capital could be reflecting greater liquidity requirements. On the other hand, if cash flow is signaling expectations of potential for future profitability, we might expect that less capital intensive firms would present a higher value for the coefficient, since they are more profitable. For Devereux and Schiantarelli (1990), cash flow varies in magnitude between firms and plays a more important role in larger companies than in smaller ones. The low value for the change in net working capital for more capital

\footnotetext{
${ }^{6} \mathrm{Hu}$ and Schiantarelli (1998) argue that "the ambiguous role of the classification of firms by size is due to the fact that: On the one hand, relatively large firms tend to be older, more diversified, less prone to bankruptcy, with a better know track record, and should therefore suffer less severe agency costs than small firms. Moreover, transaction costs for issuing debt or equity are likely to vary inversely with size. On the other hand, the ownership of small firms in often fairly concentrated, with managers holding significant blocks of stock, which may mitigate agency problems” (p. 469).
} 
intensive firms may be due to their greater ease in obtaining external financing, while negative values of this parameter may reflect a period of recession, as described by Fazzari and Petersen (1993). The higher level of indebtedness of such companies may genuinely reflect their greater ease in obtaining external financing. We might thus expect such companies to have a significant external financing coefficient, which would explain their investment. At the same time, the lower degree of indebtedness of companies with a lower degree of capital intensity is due to greater difficulty in obtaining external.

Table 2 - Characteristics of Firms by Capital Intensity - Average Values.

\begin{tabular}{|c|c|c|}
\hline Variables & Low & High \\
\hline Investment/Capital Stock & 0.411407 & 0.064702 \\
\hline Cash Flow/ Capital Stock & 0.440168 & 0.283681 \\
\hline Sales/Capital Stock & 3.683598 & 1.231212 \\
\hline Debt/Capital Stock & 0.540989 & 0.411606 \\
\hline Debt/Short-Term Capital Stock & 0.195806 & 0.143569 \\
\hline Debt/Long-Term Capital Stock & 0.117479 & 0.149152 \\
\hline Net Income/Capital Stock & 0.171538 & 0.078962 \\
\hline Change in Working Capital/Capital Stock & 0.062802 & -0.0306876 \\
\hline Debt/Stockholders’ Equity & 0.344694 & 1.382808 \\
\hline Number of Firms & 3,732 & 1,238 \\
\hline
\end{tabular}

\section{4 - Models, Selection and Discrimination}

The vast majority of studies on the determinants of investment by firms have used classical econometrics. One of the first attempts to apply the Bayesian method to Economics, and to the analysis of investment behavior in particular, was Tiao and Zellner (1964), who attempted to show how a priori information, together with information from the data, could be used to draw inferences regarding the parameters of the model. While in the Classical model the only information for estimation and inference is derived from the information contained in the data, in the Bayesian model two sources of information are recognized: on the parameters $\theta$, information which is contained in the data $y$, and previous 
information, not contained in the data. The combination of these two is used in the $a$ posteriori estimation of the parameters. In the Bayesian model, the process that specifies the probabilistic structure, i.e., the data generating process for the dependent variable as a function of the covariates, is composed of two functions: one that indicates the a priori knowledge, represented by the probability distribution, and denoted by $\pi(\theta)$, and another, representing the distribution of the information contained in the data, and denoted by $f(y / \theta)$, i.e. the likelihood function of the parameters. Through the combination of these sources of information, the a posteriori probability density function is obtained, which is denoted by:

$$
\pi(\theta / y)=\frac{\pi(y / \theta) \pi(\theta)}{\pi(y)} \propto \pi(\theta) \cdot f(y / \theta)
$$

Where the term on the left-hand side is the a posteriori density function and the first term on the right-hand side shows the product of the a priori function and the conditional likelihood on the data, which is proportional to the a priori distribution and the sampling distribution for the data. The term, $\pi(y)$, omitted from the second term on the right hand side of (6), is considered to be a normalization factor, which may be considered as a constant, since it does not depend on $\theta$ with fixed $y$. The a posteriori densities for the parameters can be calculated using Markov Chain Monte Carlo simulation algorithms (MCMC

\section{1 - Models}

The models estimated in this study are:

$$
\begin{aligned}
& \text { I. }-\left(\frac{I}{K}\right)_{j t}=\alpha_{j}+\omega_{t}+\beta_{1}\left(\frac{I}{K}\right)_{j t-1}+\beta_{2}\left(\frac{I}{K}\right)_{j t-1}^{2}+\beta_{3}\left(\frac{C F}{K}\right)_{j t-1}+\beta_{4}\left(\frac{S}{K}\right)_{j t-1}+\beta_{5}\left(\frac{D}{K}\right)_{j t-1}+\varepsilon_{j t} \\
& \text { II - }\left(\frac{I}{K}\right)_{j t}=\alpha_{j}+\omega_{t}+\gamma_{j t}+\beta_{1}\left(\frac{I}{K}\right)_{j t-1}+\beta_{2}\left(\frac{I}{K}\right)_{j t-1}^{2}+\beta_{3}\left(\frac{C F}{K}\right)_{j t-1}+\beta_{4}\left(\frac{S}{K}\right)_{j t-1}+\beta_{5}\left(\frac{D}{K}\right)_{j t-1}+\varepsilon_{k j t}
\end{aligned}
$$


$\mathrm{III}-\left(\frac{I}{K}\right)_{j t}=\alpha_{j}+\omega_{t}+\beta_{1}\left(\frac{I}{K}\right)_{j t-1}+\beta_{2}\left(\frac{I}{K}\right)_{j t-1}^{2}+\beta_{3}\left(\frac{C F}{K}\right)_{j t-1}+\beta_{4}\left(\frac{S}{K}\right)_{j t-1}+\beta_{5}\left(\frac{D}{K}\right)_{j t-1}+\varepsilon_{j t}$,

where

$\alpha_{j t}=\lambda^{\prime} C F_{j t}+\eta_{j t} ; j=1,2, \ldots, 497 ; t=1,2, \ldots, 10 ; X_{l t j}=$ covariates para $l=1,2, \ldots, 5$;

$\alpha_{j} \sim N\left(0, \sigma_{\alpha}^{2}\right) ; \omega_{\mathrm{t}} \sim N\left(0, \sigma_{\omega}^{2}\right) ; \varepsilon_{j t} \sim N\left(0 ; \sigma^{2}\right) ; \eta_{j t} \sim N\left(0, \sigma_{\eta}^{2}\right)$.

Model I intends to replicate a Classical econometrics fixed-effect model. For that, some adaptations are necessary to maintain equivalence since, from a Bayesian perspective, the estimated parameters are treated as random ${ }^{7}$. In order to achieve equivalence, we assume a diffuse a priori distribution in order to obtain the a posteriori densities. Factors influencing investment decisions may vary over time for each firm, depending on macroeconomic conditions, and even on other variables affecting firm's decisions which are not included in the model. Considering the highly turbulent macroeconomic scenario considered in this study, it seems relevant to test if factors influencing decisions were differentiated over time, and, if so, if all firms have moved in the same direction. In order to accomplish that, in Model II, we incorporate an interaction between firm and time, $\gamma_{j t}$., to verify whether there is any effect arising from the combination of firm-specific and time effects, i.e., whether both act simultaneously.

In models I and II the $\alpha_{j}$ are firm-specific effects, representing non-observed timeconstant firm's characteristics. In the literature, these characteristics are interpreted as managerial skills (Hoch, 1962), or technical efficiency (Mudlak, 1961). If these characteristics do affect cash-flow management, firms with different managerial skills could make investment decisions based on distinct factors (Nerlove, 2002). In order to check if such managerial capabilities are correlated to cash-flow, in Model III we assume that the firmspecific effect $\alpha_{j}$ is correlated with the cash flow variable, that is, $\alpha_{j}=\lambda^{\prime} C F_{j t}+\eta_{j t}$.

Since we use a hierarchical Bayesian approach, it is necessary to choose the a priori probability densities for the parameters, defined in two stages:

\footnotetext{
${ }^{7}$ Gelman et al. (1995) consider that the estimation of the fixed effect model in Bayesian form can cause some confusion: “The terms 'fixed' and 'random' come from the non-Bayesian statistical tradition and are somewhat confusing in a Bayesian context where all unknown parameters are treated as 'random'. The non-Bayesian view considers fixed effects to be fixed unknown quantities, but the standard procedures proposed to estimate parameters, based on specified repeated sampling properties, happen to be equivalent to the Bayesian posterior inference under a non-informative (uniform) prior distribution (p. 368-69).
} 
First stage:
(i) $\alpha_{j} \square N\left(0, \sigma_{\alpha}^{2}\right) ; \quad j=1,2, \ldots, 497$;
(ii) $\omega_{t} \square N\left(0, \sigma_{\omega}^{2}\right) ; \quad t=1,2, . ., 10 ;$
(ii) $\gamma_{j t} \square N\left(0, \sigma_{\gamma}^{2}\right) ; \quad t=1,2, . ., 10 ; j=1,2, \ldots, 497$
(iv) $\beta_{l} \square N\left(a_{l}, b_{l}^{2}\right)$; known $a_{l}, b_{l} ; l=1,2, \ldots 5$;
(v) $\lambda \square N\left(a_{6}, b_{6}^{2}\right)$; known $a_{6}, b_{6}$;
(vi) $\sigma^{2} \square I G\left(a_{7}, b_{7}\right)$; known $a_{7}, b_{7}$;

Second stage:

(vii) $\sigma_{\alpha}^{2} \square I G\left(a_{8}, b_{8}\right)$; known $a_{8}, b_{8}$;

(viii) $\sigma_{\omega}^{2} \square I G\left(a_{9}, b_{9}\right)$; known $a_{9}, b_{9}$;

(ix) $\sigma_{\gamma}^{2} \square I G\left(a_{10}, b_{10}\right)$; known $a_{10}, b_{10}$.

(x) $\sigma_{\eta}^{2} \square I G\left(a_{11}, b_{11}\right)$; known $a_{11}, b_{11}$.

Considering that the a priori distributions for the parameters defined above are independent, combining (10) and (11) using Bayes' formula in (6), we obtain the joint $a$ posteriori distributions for each model ${ }^{8}$. MCMC was used to obtain the sample of the $a$ posteriori joint distribution (Gelfand and Smith, 1990); (Chib and Greenberg, 1996).

\section{2 - Discrimination and Selection}

In the discrimination, analysis and selection of the models, we used Gelman and Rubin's (1992) convergence criterion and the predictive ordinate criterion. For each model, 3 chains of 10,000 observations were generated for each parameter of interest, using $a$ posteriori conditional distributions. For each chain, the first 5,000 iterations were burned, with every $20^{\text {th }}$ observation selected to arrive at a final sample of 5,000 observations for each

\footnotetext{
${ }^{8}$ The hiperparameter values in the prior distribuition were chosen to have diffuse prior distribuition. For the $\lambda$ parameter we chosed a prior with a small value for the variance to guarantee the convergence of Gibbs Sampling Algorithm.
} 
parameter. Table 3 shows values close to 1 for the Gelman and Rubin's convergence criterion., indicating convergence of the Gibbs Sampling algorithm for the parameters.

Table 3 - Gelman and Rubin Indices.

\begin{tabular}{cccccccccc}
\hline Models & $\boldsymbol{\beta}_{\mathbf{1}}$ & $\boldsymbol{\beta}_{\mathbf{2}}$ & $\boldsymbol{\beta}_{\mathbf{3}}$ & $\boldsymbol{\beta}_{\mathbf{4}}$ & $\boldsymbol{\beta}_{\mathbf{5}}$ & $\boldsymbol{\sigma}_{\varepsilon}{ }^{2}$ & $\boldsymbol{\sigma}_{\gamma}{ }^{2}$ & $\boldsymbol{\sigma}_{\eta}{ }^{2}$ & $\boldsymbol{\lambda}$ \\
\hline I & 1.001 & 1.000 & 0.9992 & 1.000 & 0.9998 & 0.9979 & ----- & ----- & ----- \\
II & 1.004 & 0.9998 & 1.000 & 1.002 & 1.002 & 1.005 & 1.295 & ----- & ----- \\
III & 1.0 & 0.9995 & 1.008 & 1.004 & 1.003 & 0.999 & --- & 1.003 & 0.9985 \\
\hline
\end{tabular}

We selected the model that best explained by the data and showed the higher predictive density using the predictive ordinate density criterion ${ }^{9}$. The choice of a point predictor for $\mathrm{Y}$ was made in accordance with a potential loss function ${ }^{10}$. The criterion for model selection based on a posteriori predictive ordinate uses the MCMC simulation method (Raftery, 1995; Gelfand and Dey, 1994).

Predictive densities for each regression model for $y_{j t}$, given the vector $y_{(j t)}$, are given by:

$$
c_{i}=f\left(y_{j t} / y_{(j t)}, x_{j t}\right)=\int \ldots \int f\left(y_{j t} /{\underset{\sim}{l j t}}_{l j}, x_{j t}\right) \pi\left(\underset{\sim}{\theta_{l j t}} / \underset{\sim}{y_{(j t)}}, x_{(j t)}\right) d \underset{\sim}{\theta},
$$

where $i=1,2,3 ; l=1,2, \ldots 5 ; j=1,2, \ldots, 497 ; t=1,2, \ldots, 10 ; \theta$ are the parameters of interest; $y_{(j)}=\left(y_{1}, \ldots, y_{j-1}, y_{j+1}, \ldots, y_{n}\right)$ and $x_{(i)}=\left(x_{1}, \ldots, x_{i-1}, x_{i+1}, \ldots, x_{n}\right)$ with $\pi\left({\underset{\sim l j t}{\theta j}}_{\sim_{(j t)}}, x_{j t}\right)$ is the $a$ posteriori distribution, given $\underset{\sim}{y_{(j t)}}$. On the basis of the samples generated by the Gibbs Sampling algorithm, the density in (9) may be approximated by the Monte Carlo estimate as:

$$
\hat{c}_{i}=\hat{f}\left(y_{j t} / y_{(j t)}, x_{j t}\right)=\frac{1}{s} \sum_{s=1}^{S} f\left(y_{j t} / \theta_{\sim j t}^{(s)}\right)
$$

\footnotetext{
${ }^{9}$ Another criterion frequently used is the Bayes Factor, defined as the ratio of the marginal likelihoods for the models for which comparison is sought. Since it is highly sensitive to the a priori choice, especially to a diffuse a priori probability, as well as to the number of parameters, we decided to use the predictive ordinate criterion. ${ }^{10}$ According to Gamerman (1997), the advantage of this approach "lies in the fact that it allows for unambiguous judgments and thus has a clear and unquestionable meaning. A prediction may always be compared with reality in a way that estimation can never be” (p. 167).
} 
We compare the models through the predictive ordinate density method with two indexes: $c(l)=\prod_{i=1}^{n} c_{i}(l)$, where $l$ indicates the model and $c(l)$ is the predictive ordinate density for each observation, and $\log \operatorname{de} c(l)=\log \left(\prod_{i=1}^{n} \hat{c}_{i}\right)=\sum_{i=1}^{n} \log \hat{c}_{i}$, choosing the model with the highest value of $\hat{c}(l)$. The values obtained are: $c(I)=5,008.68, c(I I)=2,913.26$, and $c(I I I)=9,504.48$, indicating that Model III is preferable.

\section{5 - Results}

Table 4 shows the results, indicating that cash-flow, sales and debt are significant for all models. The overall differences in the estimated parameters for models I and II are negligible. Model III shows smaller values for all coefficients, with the smallest difference being for cash-flow (24\% lower); in the other cases, differences are much larger. In Table 5 we present the results of the same three models, estimated separately for the two groups, in order to observe the differences in coefficients of all variables. In general, the coefficients of the relevant variables are larger for capital-intensive firms, with the difference being smaller for sales.

Considering the size of the coefficients, cash-flow is by far the most influent variable in investment decisions of these firms. The significance (although only at $10 \%$ for the first two models) of the coefficient for the slope dummy indicates that its importance differs across groups of firms. Its sign indicates that it is less important for low-intensity firms. Since the coefficient for all companies is around .13 for models I and II, the coefficient for lowintensity firms is around .03; for model III, it is .046. This could indicate that capitalintensive firms are more sensitive to fluctuations in their internal resources, possibly from a greater preference for the use of internal funds. Hsiao and Tahmiscioglu (1997) note that if liquidity influences current investment spending, then we should expect higher coefficients for more capital intensive firms, due to high fixed costs and greater capital demands by such companies. According to Devereux and Schiantarelli (1990), the higher cash flow coefficient for larger firms could reflect the possibility that such firms are more likely to have relatively low cash flow and a more diversified ownership structure, which would tend to increase agency costs. For Schaller (1993), firms with a more concentrated ownership structure are less 
dependent on cash flow than firms with a more diversified ownership structure, due to the reduction in conflicts of interest between shareholders and the firm's managers that would reduce agency costs.

Table 4 - Estimated Parameters.

\begin{tabular}{|c|c|c|c|c|}
\hline Variables & $\mathbf{N}$ & Model I & Model II & Model III \\
\hline$(\mathrm{I} / \mathrm{K})_{\mathrm{t}-1}$ & 5.000 & $\begin{array}{l}-0.2314 \\
(0.0287)\end{array}$ & $\begin{array}{l}-0.2315 \\
(0.0288)\end{array}$ & $\begin{array}{c}-0.03537 \\
(0.01563)\end{array}$ \\
\hline$(\mathbf{I} / \mathbf{K})^{2}{ }_{t-1}$ & 5.000 & $\begin{array}{c}0.0133 \\
(0.0037)\end{array}$ & $\begin{array}{c}0.0133 \\
(0.0037)\end{array}$ & $\begin{array}{c}0.001399 \\
(0.002043)\end{array}$ \\
\hline$(\mathrm{CF} / \mathrm{K})_{\mathrm{t}-1}$ & 5.000 & $\begin{array}{c}0.1329 \\
(0.0576)\end{array}$ & $\begin{array}{c}0.1323 \\
(0.05763)\end{array}$ & $\begin{array}{c}0.1009 \\
(0.02998)\end{array}$ \\
\hline$(\mathrm{S} / \mathrm{K})_{\mathrm{t}-1}$ & 5.000 & $\begin{array}{c}0.0199 \\
(0.0032)\end{array}$ & $\begin{array}{c}0.020 \\
(0.00327)\end{array}$ & $\begin{array}{c}0.003648 \\
(0.001385)\end{array}$ \\
\hline$(\mathbf{D} / \mathbf{K})_{t-1}$ & 5.000 & $\begin{array}{c}0.0365 \\
(0.0136)\end{array}$ & $\begin{array}{c}0.0364 \\
(0.0137)\end{array}$ & $\begin{array}{l}0.01082 * \\
(0.00593)\end{array}$ \\
\hline $\begin{array}{c}(\mathrm{CF} / \mathrm{K})_{\mathrm{t}-1} \\
\text { Slope Dummy }\end{array}$ & 5.000 & $\begin{array}{l}-0.1029 * \\
(0.0582)\end{array}$ & $\begin{array}{c}-0.1027^{*} \\
(0.0577)\end{array}$ & $\begin{array}{c}-0.05508 \\
(0.02905)\end{array}$ \\
\hline$\sigma^{2}$ & 5.000 & 0.4349 & 0.4342 & 0.09592 \\
\hline $\mathrm{N}^{\circ}$. of Obs & ------- & 4,970 & 4,970 & 4,970 \\
\hline
\end{tabular}

Except for Model III, in which the coefficient for indebteness is only significant for low-intensity firms, the results indicate that debt is more important for capitalintensive firms. Devereux and Schiantarelli (1990) argue that small companies are at a disadvantage when they have high levels of debt, since they represent a higher risk to creditors and are less diversified, implying only limited capacity for dealing with reductions in liquidity, and hence, a higher risk of bankruptcy. This would be aggravated during periods of economic turbulence, with large fluctuations in demand, as well as during recessionary situations. Titman and Wessels (1988) also pointed out that smaller companies demonstrate a higher proportion of short-term debt. This financial practice indicates higher transaction costs for raising long-term financing, as well as greater risk of bankruptcy, thus making them more susceptible to periods of recession. 
Table 5 - Parameters Estimated by the Bayesian Method According to Capital Intensity.

\begin{tabular}{|c|c|c|c|c|c|c|c|}
\hline \multirow[b]{2}{*}{ Variables } & \multirow[b]{2}{*}{$\mathbf{N}$} & \multicolumn{2}{|c|}{ Model I } & \multicolumn{2}{|c|}{ Model II } & \multicolumn{2}{|c|}{ Model III } \\
\hline & & Low Intens & High Intens & Low Intens & High ntens & Low Intens & High Intens \\
\hline \multirow{2}{*}{$(\mathrm{I} / \mathrm{K})_{\mathrm{t}-1}$} & \multirow{2}{*}{5.000} & -0.2394 & -0.2182 & -0.239 & -0.2172 & -0.0335 & -0.0553 \\
\hline & & $(0.02923)$ & $(0.04782)$ & $(0.02916)$ & (0.04795) & (0.0157) & $(0.02557)$ \\
\hline \multirow{2}{*}{$(\mathbf{I} / \mathbf{K})^{2}{ }_{t-1}$} & \multirow{2}{*}{5.000} & 0.01518 & -0.00141 & 0.01511 & -0.00141 & 0.0014 & $-9.11 \mathrm{E}-4$ \\
\hline & & (0.00379) & (0.00809) & $(0.00376)$ & (0.00791) & $(0.0021)$ & $(.00452)$ \\
\hline \multirow{2}{*}{$(\mathrm{CF} / \mathrm{K})_{\mathrm{t}-1}$} & \multirow{2}{*}{5.000} & 0.03138 & 0.1675 & 0.03094 & 0.1649 & 0.0457 & 0.1205 \\
\hline & & $(0.014)$ & $(0.07336)$ & $(0.01412)$ & $(0.0724)$ & $(0.0127)$ & $(0.0370)$ \\
\hline \multirow{2}{*}{$(\mathrm{S} / \mathrm{K})_{\mathrm{t}-1}$} & \multirow{2}{*}{5.000} & 0.0205 & $0.02452 *$ & 0.02057 & $0.02481 *$ & 0.0033 & 0.0076 \\
\hline & & (0.0033) & $(0.01517)$ & (0.00329) & $(0.01468)$ & $(0.00140)$ & (0.059) \\
\hline \multirow{2}{*}{$(\mathrm{D} / \mathrm{K})_{\mathrm{t}-1}$} & \multirow{2}{*}{5.000} & 0.03207 & 0.1009 & 0.03176 & 0.0994 & $0.0105^{*}$ & 0.0184 \\
\hline & & $(0.01368)$ & $(0.03736)$ & (0.01383) & (0.03649) & (0.0063) & (0.0184) \\
\hline \multirow{2}{*}{$\sigma^{2}$} & \multirow{2}{*}{5.000} & 0.4343 & 0.4342 & 0.4317 & 0.4325 & 0.1011 & 0.1012 \\
\hline & & $(0.00917)$ & $(0.00913)$ & $(0.00948)$ & (0.00929) & $(0.0032)$ & $(0.00313)$ \\
\hline \multicolumn{2}{|l|}{$\mathrm{N}^{\circ}$. of Obs } & 3,732 & 1,238 & 3,732 & 1,238 & 3,732 & 1,238 \\
\hline
\end{tabular}

* Significant at the $10 \%$ level.

**Stand error in brackets.

***The dependent variable is $(\mathrm{I} / \mathrm{K})_{\mathrm{t}}$. The variable that defines capital intensity is the ratio of capital stock to sales plus variation in inventories, $(\mathrm{K} / \mathrm{V}+\Delta \mathrm{E})$. The cut-off point that defines the division of the groups is 0.15 .

Sales is significant for low-intensity firms in all models; for high-intensity firms, it is only significant at $10 \%$ in models I and II, and it is not significant in model III. Firms with lower capital intensity thus tend to rely more on sales to provide funds for their investments than high-intensity firms. This result is related to the importance of debt, for lowintensity firms tend to have more difficulty in accessing long-term financing for their investments, especially in such a restricted capital market.

As the indicators on Table 2 show, sample firms with lower capital-intensity are more profitable than more capital-intensive firms. This has importance for the interpretation of the relevance of liquidity variables in explaining investment decisions. A high sensitivity of investment to cash flow is not in itself a sufficient condition for labeling such firms as financially restricted, for the importance of cash-flow could be indicating potential for future profitability; in such a case, we would expect more profitable firms to show higher coefficients. In this study, firms with higher coefficients for cash flow are the less profitable ones. We may conclude from this that the differences in the coefficients between the groups are predominantly a reflection of the degree of financial restriction on 
firms, as opposed to the potential for future profitability. The differences in the cash-flow coefficients indicate that investment decisions of capital intensive firms are more sensitive to cash flow. Since these firms are less profitable, cash flow does not seem to act as a proxy for potential future profitability. If they were really such a proxy, we would expect the coefficient to be larger for firms with higher profits, i.e. for less capital intensive firms, which does not occur. We may thus infer that capital intensive firms may be considered more financially restricted than less capital intensive ones, for the reasons already highlighted.

Model II investigates the effects of macroeconomic conditions on investment decisions, through the introduction of an interaction variable between a firm-specific effect and a time effect. In economic terms, it appears reasonable to admit that investment decisions vary over time, and that this effect is different for each firm at a given point in time. While variation over time is principally determined by macroeconomic factors, the distinct behavior of firms arises from their different characteristics. The results nevertheless fail to indicate significant differences between the coefficients, in all models and for both groups. In this way, the same conclusions obtained for the grouped model without interaction are also valid for the model with interaction. We may thus conclude that the determinants of investment do not vary over time and for each firm simultaneously. The non-observed time effect that refers to the macroeconomic factors may be affecting all firms in a similar way, regardless of theirspecific characteristics. While both effects are significant when analyzed separately, when combined, they are not statistically significant.

\section{6 - Conclusions}

The main economic result of this study indicates that firms are subject to liquidity restrictions, most notably capital intensive firms. Their low profitability index and the statistically significant differences in the cash flow coefficients between groups provide strong evidence that the cash flow coefficient is not acting as a proxy variable for the future profitability of the firm, and that more capital intensive firms suffer greater financial restrictions. This result satisfies theoretical expectations since highly capital intensive firms tend to show a low level of profitability due to the presence of high fixed costs, in addition to the presence of a more diversified ownership structure that raises agency costs. (Schiantarelli and Devereux (1990), Hsiao and Tahmisciolglu (1997) and Schaller (1993)) $)^{11}$.

\footnotetext{
${ }^{11}$ A more diversified ownership structure is present in both large firms and more capital intensive ones.
} 
On the other hand, the lower value of cash flow coefficient for the less capital intensive firms arises from the higher proportion of retained earnings, indicating that such firms are less financially restricted than capital intensive firms. Another possible reason may come from to the fact that such firms show lower agency costs, given that they often display a more concentrated ownership structure, reducing the conflicts of interest between managers and shareholders. In such cases, cash flow would be less important for firms with a more concentrated ownership structure, as described by Schaller (1993).

The coefficient of the financing variable was not statistically significant for capital-intensive firms, indicating that such firms are not constrained by credit probably due to a more diversified ownership structure, better access to external credit markets, and availability of collaterals. On the other hand, the less capital intensive firms presented credit contraints, due to their higher degree of profitability, larger availability of cash-flow, higher proportion of short-term debt, concentrated ownership structure, and lower availability of collaterals.

The estimation of parameters by three Bayesian models corroborated expectations that more capital intensive firms would suffer greater liquidity restrictions. The recursive predictive density criterion indicated that the most preferred model is the one in which firm-specific effects are correlated with the cash flow variable. This suggests that nonobserved characteristics or effects might influence the parameters of cash-flow and financing.

\section{7 - References}

Baer, W., 2001. The Brazilian Economy: Growth and Development, Praeger, $5^{\text {th }}$ Edition.

Bond, S., Meghir, C., 1994. Dynamic Investment Models and Firm’s Financial Policy. Review of Economic Studies, 61,197-222.

Bond, S., Reenen, V., 2002. J. Microeconometric Models of Investment and Employment. ifs.org.uk/innovation/bondvanr.

Devereux, M., Schiantarelli, F., 1990. Investment, Financial Factors, and Cash Flow: Evidence from U.K Panel Data. In HUBBARD, R.G. Asymmetric Information, Corporate Finance, and Investment. Chicago: Chicago University Press.

Diamond, D., 1981. Debt Maturity Structure and Liquidity Risk. The Quarterly Journal of Economics, 106, 709-737.

Fazzari, S. M., Hubbard, G., 1988. Petersen, Bruce, C. Financing constraints and corporate investment. Brookings Papers on Economic Activity, 1, 141-95. 
Fazzari, S. M., Hubbard, G., Petersen, B., 1996. Financing Constraints and corporate investment: Response to Kaplan and Zingales. National Bureau of Economic Research, Working Paper Series 5462.

Galindo, A., Schiantarelli, F. Editors, 2003. Credit Constraints and Investment in Latin America. Inter-American Development Bank.

Gelfand, A., Dey, D., 1994. Bayesian Model Choice: Asymptotics and Exact Calculations. Journal of the Royal Statistician Society, Series B, 56, 501-514.

Gelfand, A., Smith, A., 1990. Sampling-Based Approaches to Calculating Marginal Densities. Journal of American Statistical Association, 85, 398-409.

Gelman, A. et al., 1995. Bayesian Data Analysis. Great Britain: Chapman \& Hall.

Gelman, A., Rubin, D., 1992. Inference from Iterative Simulation Using Multiple Sequences. Statistical Science, 7, 457-472.

Greene, W., 2000. Econometric Analysis. New Jersey: Prentice-Hall, 4th ed.

Hoshi, T, ; Kashyap, A. K., Scharfstein, D., 1991. Corporate structure, liquidity, and investment: evidence from Japanese industrial groups. Quarterly Journal of Economics, 106, 33-60.

Hsiao, C., 1986. Analysis of Panel Data. New York: Cambridge University Press, Econometric Society Monographs.

Hsiao, C., Pesaran, H., Tahmiscioglu, K., 1997. A. Bayes Estimation of Short-Run Coefficients in Dynamic Panel Data. Revised version of the paper presented at the Seventh International Conference on Panel Data, Paris, June.

Hsiao, C., Pesaran, H., Tahmiscioglu, K., 2002. Maximum likelihood estimation of fixed effects dynamic panel data covering short time periods. Journal of Econometrics, 109, 107-150.

Hsiao, C., Tahmiscioglu, K., 1997. A panel analysis of liquidity constraint and firm investment. Journal American Statistical Association, 92, 455-65.

Huntley, S., 1993. Asymmetric information, liquidity constraints, and Canadian investment. Canadian Journal of Economics, 26, 552-74.

Jorgenson, W. D., 1996. Investment Capital Theory and Investment Behavior. USA: MIT Press, vol.1.

Kaplan, S., Zingales, L., 1997. Do investment-cash flow sensitivities provide useful measures of financing constraints? Quarterly Journal of Economics, 122, 169-215.

Kass, R., Raftery, A., 1995. Bayes Factors. Journal of the American Statistician Association, 90, 773-795.

Kiviet, J., 1995. On bias, inconsistency, and efficiency of various estimators in dynamic panel data models. Journal of Econometrics, 68, 53-78.

Lancaster, T., 2004. An Introduction to Modern Bayesian Econometrics. USA: Blackwell Publishing Ltd.

Modigliani, F., Miller, M., 1958. The Cost of Capital, Corporation Finance and the Theory of Investment. The American Economic Review, 48, 162-97.

Myers, S., Majluf, N., 1984. Corporate financing and investment decision when firms have information that investors do not have. Journal of Financial Economics, 13, 187-221.

Nerlove, M. L., 2002. Essays in Panel Data Econometrics, New York: Cambridge University Press 
Oliner, S., Rudebusch, G., 1996. Is There a Broad Credit Channel for Monetary Policy? FRBSF Economic Review, 4, 3-13.

Raftery, A., 1995. Hypothesis Testing and Model Selection with Posterior Simulation. In Gilks, R.W.; Richardson, S. And Spiegelhalter, D. J.;. Practical Markov Chain Monte Carlo. London: Chapman and Hall.

Scherer, F., 1980. Industrial Market Structure and Economic Performance. New York: Houghton Mifflin.

Schiantarelli, F., 1996. Financial Constraints and Investment: Methodological Issues and International Evidence. Oxford Review of Economics Policy, 12, 70-89.

Schiantarelli, F., Hu, X., 1998. Investment and Capital Market Imperfections: A Switching Regression Approach Using U. S Firm Panel Data. The review of Economics and Statistics, 80, 466-479.

Tahmiscioglu, K., 2001. A. Intertemporal Variation in Financial Constraints on Investment: A Time-Varying Parameter Approach Using Panel Data. Journal of Business \& Economic Statistical, 19, 153-165.

Tiao, G., Zellner, A., 1964. Bayes' Theorem and the Use of Prior Knowledge in Regression Analysis. Biometrika, 51, 219-230.

Wooldridge, J., 2002. M. Econometric Analysis of Cross Section and Panel Data. USA:MIT Press.

Xiaoqiang, H., Schiantarelli, F., 1994. Investment and financing constraints: a switching regression approach using U. S. firms panel data. Boston College department of economics. Working Paper, 284. 